\title{
Mental health and substance use among women and men at the intersections of identities and experiences of discrimination: insights from the intersectionality framework
}

\author{
Milkie Vu ${ }^{1 *}$, Jingjing $\mathrm{Li}^{1}$, Regine Haardörfer ${ }^{1}$, Michael Windle ${ }^{1}$ and Carla J. Berg ${ }^{1,2}$
}

\begin{abstract}
Background: Intersectionality theory focuses on how one's human experiences are constituted by mutually reinforcing interactions between different aspects of one's identities, such as race, class, gender, and sexual orientation. In this study, we asked: 1) Do associations between intersecting identities (race and sexual orientation) and mental health (depressive symptoms) and substance use (alcohol, tobacco, and marijuana) differ between men and women? and 2) How do single or intersecting self-reports of perceived racial and/or sexual orientation discrimination influence mental health and substance use outcomes for men and women? We compared results of assessing identities versus experiences of discrimination.

Methods: Multivariable regressions were conducted on cross-sectional data from 2315 Black and White college students. Predictors included measures of sociodemographic characteristics and experiences of discrimination. Outcomes included past 2-week depressive symptoms (PHQ-9), past 30-day alcohol use, past 30-day tobacco use, and past 30-day marijuana use.

Results: Intersecting identities and experience of discrimination had different associations with outcomes. Among women, self-reporting both forms of discrimination was associated with higher depressive symptoms and substance use. For example, compared to women experiencing no discrimination, women experiencing both forms of discrimination had higher depressive symptoms $(B=3.63, C l=[2.22-5.03])$, alcohol use $(B=1.65, C l=[0.56-2.73])$, tobacco use $(\mathrm{OR}=3.45, \mathrm{Cl}=[1.97-6.05])$, and marijuana use $(\mathrm{OR}=3.38, \mathrm{Cl}=[1.80-6.31])$. However, compared to White heterosexual women, White sexual minority women had higher risks for all outcomes $(B=3.16$ and $C l=[2.03-4.29]$ for depressive symptoms, $\mathrm{B}=1.45$ and $\mathrm{Cl}=[0.58-2.32]$ for alcohol use, $\mathrm{OR}=2.21$ and $\mathrm{Cl}=[1.32-3.70]$ for tobacco use, and $\mathrm{OR}=3.01$ and $\mathrm{Cl}=[1.77-5.12]$ for marijuana use); while Black sexual minority women had higher tobacco $(\mathrm{OR}=2.64$, $\mathrm{Cl}=[1.39-5.02])$ and marijuana use $(\mathrm{OR}=2.81, \mathrm{Cl}=[1.33-5.92])$ only. Compared to White heterosexual men, White sexual minority men had higher depressive symptoms $(B=1.90, C l=[0.52-3.28])$ and marijuana use $(\mathrm{OR}=2.37, \mathrm{Cl}=[1.24-4.49])$.

\footnotetext{
* Correspondence: milkie.vu@emory.edu

'Department of Behavioral Sciences and Health Education, Rollins School of

Public Health, 1518 Clifton Rd NE, Atlanta, GA 30322, USA

Full list of author information is available at the end of the article
}

(c) The Author(s). 2019 Open Access This article is distributed under the terms of the Creative Commons Attribution 4.0 International License (http://creativecommons.org/licenses/by/4.0/), which permits unrestricted use, distribution, and reproduction in any medium, provided you give appropriate credit to the original author(s) and the source, provide a link to the Creative Commons license, and indicate if changes were made. The Creative Commons Public Domain Dedication waiver (http://creativecommons.org/publicdomain/zero/1.0/) applies to the data made available in this article, unless otherwise stated. 
(Continued from previous page)

Conclusions: Our results highlight the deleterious impacts of racial discrimination and sexual orientation discrimination on health, in particular for women. Future studies should distinguish between and jointly assess intersecting social positions (e.g., identities) and processes (e.g., interpersonal experience of discrimination or forms of structural oppression).

Keywords: Intersectionality, Racial discrimination, African-Americans, Sexual orientation discrimination, Substance use, Mental health, Young adult college students, Word count (manuscript body): 4924 words.

\section{Background}

\section{Application of intersectionality theory in public health research}

Intersectionality theory highlights how one's human experiences are constituted by mutually reinforcing interactions between different aspects of one's identities, such as race, class, gender, and sexuality [1]. Intersectionality as an analytical concept for the social and health sciences has its roots in black feminist scholarship. In the seminal article "Mapping the margins: Intersectionality, identity politics, and violence against women of color," Crenshaw pointed out that "the intersection of racism and sexism factors into Black women's lives in ways that cannot be captured wholly by looking at the race or gender dimensions of those experiences separately" [2]. While Crenshaw focused mainly on the intersection of sex and race, she also highlighted the need to investigate aspects of one's identity that extend beyond these two categories, as well as the ways in which these intersecting aspects create lived experiences embedded in structural systems of opportunities and oppression.

Crenshaw's arguments are further extended in works by others such as Bowleg $(2008 ; 2012)$ and Bauer (2014). For example, Bowleg asserted that intersectionality should be applied as an analytical theoretical framework as opposed to a traditional theory with operationalized and empirically testable variables $[3,4]$. Additionally, the core tenet and starting point of intersectionality should be "multiple socially disadvantaged statuses," or in other words, historically oppressed and marginalized populations such as racial or sexual minority populations [4]. In regard to modeling intersectionality through statistical methods, Bauer emphasized the need to distinguish between variables capturing intersecting identities (e.g., race or sexual orientation) and positions (e.g., racism or homophobia), as well as the need to structure statistical models properly to make differential effects visible across strata or groups [5]. While intersectionality arises from the more historical, interpretative, and qualitative perspectives in the social sciences [6], the abovementioned works have been fundamental in providing more concrete theoretical and methodological directions for quantitatively modeling intersectionality in public health research.
Recent years have seen a proliferation in the number of health studies using intersectionality as a guiding framework along with increasing appreciation of its potential for investigating social determinants of health [7]. Intersectionality has been explicitly applied in research examining disparities or differences in a variety of health beliefs, behaviors, and outcomes, including mental health $[6,8]$ and substance use [9]. In addition to examining the intersection of identity categories typically seen in public health, such as age, sex, race, sexual orientation, and socioeconomic status, recent studies have also incorporated other measures accounting for social phenomena that reflect power and oppression [10]. Intersections of different experiences of discrimination have also received increasing attention $[11,12]$.

\section{The relationship between discrimination and mental health and substance use}

Central to the intersectionality theory is the idea that multiple social identities at the micro-level (e.g., race, sex, or social class) are linked to macro- and structural-level inequalities (e.g., racism, sexism, and poverty) [3, 4]. This idea is shared with the minority stress theory. Minority stress theory posits that individuals with membership in a minority group will experience unfair treatment due to their group membership [13-15]. Similar to intersectionality theory, minority stress theory hypothesizes that discrimination plays an important role in explaining health disparities between dominant and minority groups.

Several pathways have been proposed for how interpersonal discrimination negatively affects health outcomes and increases health risk behaviors. In regard to mental health, interpersonal and direct experiences with discrimination can lead to heightened vigilance, challenge one's beliefs about fairness and justice, create internalized stigma towards oneself, and exacerbate physiological and psychological stress, all of which contribute to poorer mental health outcomes [14, 16-18]. A meta-analysis of 110 studies found a significant negative correlation between experiences of perceived discrimination and mental health status [19].

Regarding substance use (e.g., alcohol, tobacco, and marijuana), experiences of discrimination can prompt adolescents and young adults to increase their affiliation 
with drug-using peers, which subsequently may lead to higher substance use [20]. In addition, individuals exposed to discrimination are more likely to endorse substance use as a coping mechanism [21, 22]. Moreover, psychological distress as a result of experiences of discrimination has also been shown to play a mediating role in the relationship between discrimination and substance use [23-25].

\section{Issues in the application of intersectionality}

Two interrelated challenges appear in the application of intersectionality in public health. The first issue is the tension between the intersectionality paradox and the multiple jeopardy perspective (also known as multiple disadvantages or multiple-hierarchy stratification approach). Bowleg emphasized the "intersectionality paradox" as one of the most noteworthy contributions of intersectionality theory to public health [4]. According to Bowleg, "low"-status social identities (e.g., racial or sexual minority) do not automatically equate disadvantages; rather, they intersect with "high"-status identities (e.g., high socioeconomic status) to produce differences in outcomes. An example of the "intersectionality paradox" could be seen in Rosenfield's study on mental health at the intersection of sex, race, and class [8]. The study demonstrated that, among women with higher than a high school education, Black women have lower rates of depression than White; among women with lower education levels, there were no significant differences between the two groups. These different patterns for women were not indicated in Black versus White men in the study.

While the multiple jeopardy approach also investigates the impacts of multiple social identities and statuses, this perspective assumes that disadvantages accumulate in an added-burden or additive fashion. With additional minority statuses, individuals are assumed to be at risk for incrementally poorer health [14, 26-28]. For example, at the intersections of race, sex, and sexual orientation, a woman who is Black and sexual minority is assumed to have worst health outcomes (i.e., three "low"-status identities), whereas a man who is White and heterosexual would have best health outcomes (i.e., three "high"-status identities). In recent years, scholars have identified discrepancies in findings for the multiple jeopardy and criticized this approach for oversimplifying social realities $[8,29]$, though there still remains a need for more empirical data to address these issues.

The tension between the intersectionality and multiple jeopardy approaches also points to a need to reevaluate measurements in public health and, in particular, the need to distinguish between identity and experience. Frequently, studies in this research area do not include measures for discrimination, and many studies still treat disadvantaged statuses or minority identities as identical to, or an approximation for, experiences of discrimination. For example, a commonly seen approach is when studies report a poorer health outcome or increased health risks for a minority group, they often hypothesize that the differences may be due to impacts of interpersonal discrimination, without actually including a measure for discrimination [30,31]. While it is logical and consistent with minority stress theory to posit that individuals with minority statuses will face stigma due to their membership in the minority groups, it is problematic to assume that these two domains (identity and experience) are interchangeable or synonymous.

In light of the tensions of how intersectionality has been developed and applied in public health, this paper seeks to contribute to the field by investigating the following two questions: 1) Do associations between intersecting identities (i.e. race and sexual orientation) and mental health (depressive symptoms) and substance use (alcohol, tobacco, and marijuana) differ between men and women? and 2) How do single or intersecting self-reports of perceived racial and/or sexual orientation discrimination influence mental health and substance use outcomes for men and women? In answering these two questions, we compare results of assessing identities versus experiences of discrimination on health behaviors and outcomes. The goal of this research is to provide empirical evidence supporting the need to: 1 ) incorporate understanding of differing mental health and substance use outcomes based on intersections of identities and intersections of experiences of discrimination, and 2) distinguish between the two domains of identity and experience in public health research.

\section{Methods}

\section{Study design and participants}

Data for the current study came from Project DECOY (Documenting Experiences with Cigarettes and Other Tobacco in Young Adults). The methods employed for sampling and recruitment for Project DECOY have been described elsewhere [32]. Briefly, this is a two-year, six-wave longitudinal cohort study that involved 3418 racially/ethnically diverse students (ages 18 to 25 years) from seven colleges and universities in Georgia. Schools are located in both rural and urban settings and include two public universities/colleges, two private universities, two community/technical colleges, and one historically black university. Our project was approved by the Emory University and ICF Institutional Review Boards (IRBs) as well as the IRBs of the participating colleges and universities. Data collection began in Fall 2014 and consisted of self-report assessments via an online survey every four months for two years (during Fall, Spring, and Summer). 
The registrar's office from each campus provided e-mail addresses for English-speaking students ages 1825. We randomly selected 3000 email addresses from each of the three largest campuses, and emailed a census of students at the four smaller campuses with fewer than 3000 students. We met our sampling quota target in a short time interval $(24 \mathrm{~h}$ at the private schools to seven days at the technical colleges) and enrolled between 12.0 to $59.4 \%$ of those approached at different campuses, and overall $22.9 \%(N=3574 / 15,607)$. Seven days after initial recruitment and completion of the baseline survey, we asked participants to confirm their participation by clicking a "confirm" button included in an email sent to them. The email reiterated the tasks involved in the study and its timeline. Once participants clicked "confirm," they were enrolled into the study and sent their first incentive in the form of a $\$ 30$ gift card via email. The confirmation rate was $95.6 \%(N=3418 / 3574)$. Our intent was to enroll participants who were engaged in email and were potentially more likely to be retained in the subsequent waves of the larger, multi-wave longitudinal project.

The current analyses examined data from Wave 5 of the study. Data were collected between April and May 2016, which took place around 1.5 years from the baseline (Wave 1) data collection. Wave 5 surveys were completed by 2690 participants (the retention rate from Wave 1 to Wave 5 is 78.7\%). Since our research questions focused on participants who identified as Black or White, a total of 2315 participants who met this criterion were included in the analyses.

\section{Measures}

Data were taken from the baseline survey assessments of socio-demographic information and the Wave 5 assessment of experience of discrimination, depressive symptoms, and use of alcohol, tobacco, and marijuana within the past 30 days.

\section{Sociodemographic Characteristics}

Sociodemographic factors captured in the surveys included sex $(0=$ Male, $1=$ Female $)$, race $(0=$ White, $1=$ Black), sexual orientation $(0=$ Heterosexual, $1=$ Sexual minority), age, highest level of education attained by parents $(0=$ Bachelor's degree \& above, $1=$ Below a Bachelor's degree), and school type $(0=$ Private school, $1=$ State university, $2=$ Technical college, and $3=$ Historically black college/university (HBCU)).

\section{Experience of discrimination}

Experience of discrimination were assessed with: "How often have you felt as though you were treated badly because of your race or ethnicity?" and "How often have you felt as though you were treated badly because of your sexual orientation?" Response options for both questions ranged from $1=$ Never to $5=$ Very often. These questions were adapted from measures used in previous works on racial and ethnic discrimination in youth in the United States [33, 34].

Sensitivity analyses were conducted to see if results differed significantly when the variables were operationalized as ordinal variables (score ranging from 1 to 5 ) and as binary categorical variables (ever versus never having any experience with discrimination). Because results did not significantly change, we conceptualized the discrimination variables as binary categorical variables and dichotomized responses to either $0=$ never having any experience with discrimination or $1=$ ever having any experience with discrimination.

\section{Outcome: Depressive symptoms}

Depressive symptoms were assessed using the Patient Health Questionnaire-9 (PHQ-9), a nine-item assessment scale using diagnostic criteria for depressive disorders from the Diagnostic and Statistical Manual of Mental Disorders (DSM)-IV [35]. The items asked participants whether they had been bothered by any of the listed problems (e.g., "feeling down, depressed, or hopeless") during the previous two weeks. Response options ranged from $1=$ Not at all to $4=$ Nearly every day. Summed scores across all nine items were created for each participant. Cronbach's alpha for the PHQ-9 was 0.90 .

In our sample, any participant who chose "Refuse" on an item in the PHQ-9 scale was coded as having missing data for that item. For the PHQ-9, it had been suggested that if participants had missing data for one or two out of the nine items, the missing values should be substituted with the average score of the non-missing items. Participants with missing data for more than two items should be coded as having missing data for the summed scores [36]. All participants with missing PHQ-9 data in our sample $(n=31)$ had missing data for more than two items and were all coded as having missing data for the summed score.

\section{Outcome: Use of alcohol}

Use of alcohol was assessed with: "In the past 30 days, on how many of those days did you drink alcohol?" Response options ranged from 0 to 30 days.

\section{Outcome: Use of tobacco products}

Use of tobacco products was assessed with: "During the past 30 days, on how many days did you: smoke cigarettes; smoke little cigars or cigarillos; use a smokeless tobacco product; use an e-cigarette; or use a hookah or waterpipe?" Given the highly right-skewed distribution of this variable, responses were dichotomized into $0=$ no 
days of use for all products or $1=$ one or more days of use of any tobacco product.

\section{Outcome: Use of marijuana}

Use of marijuana was assessed with: "During the past 30 days, on how many days did you use marijuana?" Given the highly right-skewed distribution of this variable, responses were dichotomized into $0=$ no day of use or $1=$ one or more days of use.

\section{Data analysis}

Simple logistic regressions were conducted to assess the association between race and experience of racial discrimination as well as the association between sexual orientation and experience of sexual orientation discrimination. We found that being Black was associated with reporting racial discrimination (odd ratio or $\mathrm{OR}=7.46$, $p<0.001$ ), and being sexual minority was associated with reporting sexual orientation discrimination $(\mathrm{OR}=42.67$, $p<0.001)$. We also conducted bivariate analyses to examine sociodemographic characteristics and experience of discrimination in relation to the four outcomes of interest: 1) number of depressive symptoms; 2) number of days of alcohol use within the past 30 days; 3 ) use of any tobacco products within the past 30 days; and 4) use of marijuana within the past 30 days.

Multivariable linear and binary logistic regression models were used to identify correlates of the outcomes of interest. Given evidence on sex differences in depression and substance use behaviors (refer to Table 1), for each outcome, we stratified models by sex. We then constructed two different multivariable regression models (for a total of four models per outcome). For each outcome, Model 1 contained variables capturing intersecting identities (White and heterosexual, White and sexual minority, Black and heterosexual, or Black and sexual minority), and Model 2 contained variables capturing experience of discrimination (no experience, only racial discrimination, only sexual orientation discrimination, or both forms of discrimination). Key sociodemographic variables (age, highest parental education, and school type) were also entered into all models. In our data, we observed that $70.91 \%$ of Black students reported experiencing racial discrimination compared to $24.63 \%$ of White students; moreover, $2.85 \%$ of heterosexual students reported experiencing sexual orientation discrimination compared to $55.56 \%$ of sexual minority students. We also observed a high correlation between race and experience of racial discrimination as well as between sexual orientation and experience of sexual orientation discrimination $(\mathrm{OR}=7.46$ and $\mathrm{OR}=42.67$, respectively, with both $\mathrm{p}$ values $<0.001$, as noted above). Therefore, we did not include race and experience of racial discrimination in the same model. We also did not include sexual orientation and experience of sexual orientation discrimination in the same model. Analyses were conducted using SAS 9.4.

\section{Results}

The average age at baseline was 20.49 years (standard deviation or SD $=1.91), 65.75 \%(n=1522)$ was female, $25.10 \%(n=581)$ was Black, and $11.00 \%(n=252)$ was sexual minority. Among women, 7.24\% $(n=109)$ were White sexual minority, $4.12 \%(n=62)$ were Black sexual minority, and 26.78\% ( $n=403)$ were Black heterosexual. Among men, 8.15\% $(n=64)$ were White sexual minority, $2.17 \%(n=17)$ were Black sexual minority, and $11.21 \%(n=88)$ were Black heterosexual.

Racial discrimination was reported by $36.24 \%(n=$ 839), and experience of sexual orientation discrimination was reported by $8.77 \%(n=203)$ of participants. The average score on PHQ-9 was 5.24 (SD = 5.62), and the average number of days of using alcohol within the past 30 days was $3.58(\mathrm{SD}=4.99)$. Within the past 30 days, $17.42 \%(\mathrm{n}=399)$ of participants reported use of tobacco products, and $12.52 \%(n=278)$ reported use of marijuana. Table 1 provides additional characteristics of the study participants.

\section{Depressive symptoms}

In bivariate analyses, higher depressive symptoms was associated with being female, sexual minority, reporting racial discrimination, reporting sexual orientation discrimination, younger age, having parents with highest education being below a Bachelor's degree, and school type.

Multivariable linear regression models (shown in Table 2) indicated that compared to White heterosexual women, White sexual minority women had higher depressive symptoms (beta or $\mathrm{B}=3.16, p<0.001$ ). Compared to women who experienced no discrimination, women who experienced only racial discrimination $(\mathrm{B}=$ $1.57, p<0.001)$, only sexual orientation discrimination $(\mathrm{B}=2.59, p<0.001)$, and both forms of discrimination $(\mathrm{B}=3.63, p<0.001)$ had higher depressive symptoms. For women, older age was associated with lower depressive symptoms.

Compared to White heterosexual men, White sexual minority men had higher depressive symptoms $(B=1.90$, $p=0.01$ ). Compared to men who experienced no discrimination, men who experienced only racial discrimination $(\mathrm{B}=0.96, p=0.03)$ and only sexual orientation discrimination $(\mathrm{B}=3.78, p<0.001)$ had higher depressive symptoms.

\section{Use of alcohol}

In bivariate analyses, higher number of days of alcohol use within the past 30 days was associated with being male, White, and sexual minority, as well as older age, 
Table 1 Characteristics of study participants in relations to sex (bivariate analyses)

\begin{tabular}{|c|c|c|c|c|}
\hline Characteristics & $\begin{array}{l}\text { Total Sample } N= \\
2315 \\
\mathrm{~N}(\%) \text { or } \mathrm{M}(\mathrm{SD})\end{array}$ & $\begin{array}{l}\text { Women }(\mathrm{N}= \\
1522) \\
\mathrm{N}(\%) \text { or } \mathrm{M}(\mathrm{SD})\end{array}$ & $\begin{array}{l}\text { Men }(N=793) \\
N(\%) \text { or } M(S D)\end{array}$ & $p$ \\
\hline Age (SD) & $20.49(1.91)$ & $20.50(1.89)$ & $20.48(1.97)$ & .84 \\
\hline \multicolumn{5}{|l|}{ Sex } \\
\hline Male & 793 (34.25\%) & & & \\
\hline Female & $1522(65.75 \%)$ & & & \\
\hline Race & & & & $<.001$ \\
\hline White & 1734 (74.90\%) & 1047 (68.79\%) & $687(86.63 \%)$ & \\
\hline Black & $581(25.10 \%)$ & $475(31.21 \%)$ & $106(13.37 \%)$ & \\
\hline Sexual orientation ${ }^{\mathrm{a}}(N=2290)$ & & & & .45 \\
\hline Heterosexual & $2038(89.00 \%)$ & $1334(88.64 \%)$ & $704(89.68 \%)$ & \\
\hline Sexual minority & $252(11.00 \%)$ & $171(11.36 \%)$ & $81(10.32 \%)$ & \\
\hline Highest parental education $^{\mathrm{b}}(\mathrm{N}=2290)$ & & & & $<.001$ \\
\hline Bachelor's degree or above & $1222(53.36 \%)$ & $713(47.31 \%)$ & $509(65.01 \%)$ & \\
\hline Below a Bachelor's degree & $1068(46.64 \%)$ & $794(52.69 \%)$ & $274(34.99 \%)$ & \\
\hline School type & & & & $<.001$ \\
\hline Private college/university & $940(40.60 \%)$ & $564(37.06 \%)$ & $376(47.41 \%)$ & \\
\hline State university & $669(28.90 \%)$ & $371(24.38 \%)$ & $298(37.58 \%)$ & \\
\hline Technical college & $423(18.27 \%)$ & $335(22.01 \%)$ & $88(11.10 \%)$ & \\
\hline $\mathrm{HBCU}$ & $283(12.22 \%)$ & $252(16.56 \%)$ & $31(3.91 \%)$ & \\
\hline Experience of racial discrimination & Yes $=839(36.24 \%)$ & $\begin{array}{l}\text { Yes }=603 \\
(39.62 \%)\end{array}$ & $\begin{array}{l}\text { Yes }=236 \\
(29.76 \%)\end{array}$ & $<.001$ \\
\hline \multicolumn{5}{|c|}{ Blacks reporting discrimination $=412$ (70.91\% of Blacks) } \\
\hline \multicolumn{5}{|c|}{ Whites reporting discrimination $=427$ (24.63\% of Whites) } \\
\hline Experience of sexual orientation discrimination & Yes $=203(8.77 \%)^{\#}$ & Yes = 131 (8.61\%) & Yes $=72(9.08 \%)$ & .70 \\
\hline \multicolumn{5}{|c|}{$\begin{array}{l}\text { Sexual minority reporting discrimination }=140(55.56 \% \text { of sexual minority } \\
\text { students) }\end{array}$} \\
\hline \multicolumn{5}{|c|}{$\begin{array}{l}\text { Heterosexual students reporting discrimination }=58(2.85 \% \text { of heterosexual } \\
\text { students) }\end{array}$} \\
\hline Depression score $(N=2284)^{d}$ & $5.24(5.62)$ & $4.65(5.31)$ & $5.55(5.75)$ & $<.001$ \\
\hline Days of using alcohol within past 30 days & $3.58(4.99)$ & $3.13(4.51)$ & $4.45(5.69)$ & $<.001$ \\
\hline Use of any tobacco products* within past 30 days & & & & $<.001$ \\
\hline Yes & $399(17.24 \%)$ & $217(14.26 \%)$ & $182(22.95 \%)$ & \\
\hline Use of marijuana within past 30 days $^{c}(N=2220)$ & & & & .31 \\
\hline Yes & 278 (12.52\%) & 175 (12.01\%) & 103 (13.50\%) & \\
\hline
\end{tabular}

* Includes any use of cigarettes, little cigars/cigarillos, smokeless tobacco, e-cigarettes, or hookahs within the past 30 days

a Data are missing for 25 participants who chose "Refuse" ${ }^{\text {b }}$ Data are coded as missing for 25 participants who chose "Don't know"

"Data are missing for 95 participants who chose "Refuse" d Data are coded as missing for 31 participants who chose "Refuse" on items of the PHQ-9 scale

\# Discrepancy in sum is due to 4 students with missing sexual orientation data who reported discrimination

HBCU Historically Black Colleges/Universities, N Size of the Sample, M Mean, SD Standard Deviation, $p$ Probability Value

having parents with highest education of a bachelor's degree or above, and school type.

Multivariable linear regression models (shown in Table 3) indicated that, compared to White heterosexual women, White sexual minority women had higher alcohol use $(\mathrm{B}=1.45, p=0.001)$, while Black heterosexual women had lower alcohol use $(\mathrm{B}=-1.39, p<0.001)$. Compared to women experiencing no discrimination, women who experienced both racial and sexual orientation discrimination had higher alcohol use $(\mathrm{B}=1.65, p=$ $0.003)$. For both men and women, older age was associated with higher alcohol use. Compared to attending a private school, attending a technical college was associated with lower alcohol use; for women, attending a state university was associated with lower alcohol use. For both men and women, having parents with highest 
Table 2 Multivariable linear regressions on sociodemographic characteristics, intersecting identities, and intersecting experiences of discrimination and outcome of depressive symptoms (per the PHQ-9)

\begin{tabular}{|c|c|c|c|c|c|c|c|c|}
\hline & \multicolumn{4}{|c|}{ Women's depressive symptoms } & \multicolumn{4}{|c|}{$\underline{\text { Men's depressive symptoms }}$} \\
\hline & \multirow{2}{*}{$\begin{array}{l}\text { Model with } \\
\text { intersecting } \\
\text { identities } \\
\mathrm{B} \text { and } \mathrm{Cl}\end{array}$} & \multicolumn{3}{|c|}{$\begin{array}{l}\text { Model with intersecting } \\
\text { experiences of discrimination }\end{array}$} & \multirow{2}{*}{$\begin{array}{l}\text { Model with intersecting } \\
\text { identities } \\
\text { B and Cl }\end{array}$} & \multicolumn{3}{|c|}{$\begin{array}{l}\text { Model with intersecting } \\
\text { experiences of } \\
\text { discrimination }\end{array}$} \\
\hline & & $p$ & $\mathrm{~B}$ and $\mathrm{Cl}$ & $p$ & & $p$ & $\mathrm{~B}$ and $\mathrm{Cl}$ & $p$ \\
\hline Age & $\begin{array}{l}-0.24(- \\
0.40-- \\
0.09)\end{array}$ & .002 & $\begin{array}{l}-0.27(-0.43-- \\
0.12)\end{array}$ & $<.001$ & $0.08(-0.11-0.27)$ & .42 & $\begin{array}{l}0.08(-0.11- \\
0.27)\end{array}$ & .39 \\
\hline \multicolumn{9}{|l|}{ Highest parental education } \\
\hline Bachelor's degree or above & Reference & & Reference & & Reference & & Reference & \\
\hline Below a Bachelor's degree & $\begin{array}{l}0.80(0.16- \\
1.44)\end{array}$ & .01 & $0.61(-0.02-1.23)$ & .06 & $0.22(-0.64-1.08)$ & .62 & $\begin{array}{l}0.23(-0.62- \\
1.08)\end{array}$ & .59 \\
\hline \multicolumn{9}{|l|}{ School type } \\
\hline Private college/university & Reference & & Reference & & Reference & & Reference & \\
\hline State university & $\begin{array}{l}1.10(0.33- \\
1.87)\end{array}$ & .005 & $0.67(-0.08-1.43)$ & .08 & $0.83(-0.02-1.68)$ & .06 & $\begin{array}{l}0.82(-0.02- \\
1.66)\end{array}$ & .06 \\
\hline Technical college & $\begin{array}{l}-0.05(- \\
0.90-0.81)\end{array}$ & .91 & $-0.32(-1.17-0.52)$ & .45 & $-0.06(-1.42-1.30)$ & .93 & $\begin{array}{l}0.07(-1.25- \\
1.40)\end{array}$ & .91 \\
\hline $\mathrm{HBCU}$ & $\begin{array}{l}-0.37(- \\
1.54-0.80)\end{array}$ & .54 & $-1.62(-2.55-0.68)$ & $<.001$ & $-2.05(-4.46-0.37)$ & .10 & $\begin{array}{l}-1.91(-4.06- \\
0.25)\end{array}$ & .08 \\
\hline \multicolumn{9}{|l|}{ Intersecting identities } \\
\hline Being White and heterosexual & Reference & & & & Reference & & & \\
\hline Being White and sexual minority & $\begin{array}{l}3.16(2.03- \\
4.29)\end{array}$ & $<.001$ & & & $1.90(0.52-3.28)$ & .01 & & \\
\hline Being Black and heterosexual & $\begin{array}{l}-0.38 \\
(-1.27- \\
0.50)\end{array}$ & .40 & & & $0.74(-0.62-2.10)$ & .29 & & \\
\hline Being Black and sexual minority & $\begin{array}{l}0.18 \\
(-1.41- \\
1.77)\end{array}$ & .82 & & & $1.91(-0.80-4.63)$ & .17 & & \\
\hline \multicolumn{9}{|l|}{ Experience of discrimination } \\
\hline No discrimination & & & Reference & & & & Reference & \\
\hline Only racial discrimination & & & $1.57(0.93-2.21)$ & $<.001$ & & & $0.96(0.08-1.85)$ & .03 \\
\hline Only sexual orientation discrimination & & & $2.59(1.11-4.07)$ & $<.001$ & & & $3.78(2.00-5.56)$ & $<.001$ \\
\hline \multirow[t]{2}{*}{$\begin{array}{l}\text { Both racial and sexual orientation } \\
\text { discrimination }\end{array}$} & & & $3.63(2.22-5.03)$ & $<.001$ & & & $\begin{array}{l}1.44(-0.39- \\
3.27)\end{array}$ & .12 \\
\hline & Adj $R^{2}=0.04$ & & Adj $R^{2}=0.05$ & & Adj $R^{2}=0.01$ & & Adj $R^{2}=0.03$ & \\
\hline
\end{tabular}

HBCU Historically Black Colleges/Universities, $B$ Beta, CI Confidence Interval, $p$ Probability Value, $R^{2}$ Coefficient of Determination

education of less than a Bachelor's degree was associated with lower alcohol use.

\section{Use of tobacco products}

In bivariate analyses, use of tobacco products within the past 30 days was associated with being male, sexual minority, reporting racial discrimination, reporting sexual orientation discrimination, and school type.

Multivariable logistic regression models (shown in Table 4) indicated that, compared to White heterosexual women, White sexual minority women $(\mathrm{OR}=2.21, p=$ $0.003)$ and Black sexual minority women $(\mathrm{OR}=2.64, p=$ 0.003 ) were more likely to use tobacco products.
Compared to women who experienced no discrimination, women who experienced only racial discrimination $(\mathrm{OR}=$ $1.42, p=0.04)$ and both racial and sexual orientation discrimination $(\mathrm{OR}=3.45, p<0.001)$ were all more likely to use tobacco products. Additionally, for both men and women, compared to attending a private school, students attending a state university or a technical college were more likely to use tobacco products. Women attending a $\mathrm{HBCU}$ also were more likely to use tobacco products.

\section{Use of marijuana}

In bivariate analyses, use of marijuana within the past 30 days was associated with being Black, sexual minority, 
Table 3 Multivariable linear regressions on sociodemographic characteristics, intersecting identities, and intersecting experiences of discrimination and outcome of number of days of alcohol use in the past 30 days

\begin{tabular}{|c|c|c|c|c|c|c|c|c|}
\hline & \multicolumn{4}{|c|}{ Women's number of days of alcohol use } & \multicolumn{4}{|c|}{ Men's number of days of alcohol use } \\
\hline & \multicolumn{2}{|c|}{$\begin{array}{l}\text { Model with intersecting } \\
\text { identities }\end{array}$} & \multicolumn{2}{|c|}{$\begin{array}{l}\text { Model with intersecting } \\
\text { experiences of } \\
\text { discrimination }\end{array}$} & \multicolumn{2}{|c|}{$\begin{array}{l}\text { Model with intersecting } \\
\text { identities }\end{array}$} & \multicolumn{2}{|c|}{$\begin{array}{l}\text { Model with intersecting } \\
\text { experiences of } \\
\text { discrimination }\end{array}$} \\
\hline & $\mathrm{B}$ and $\mathrm{Cl}$ & $p$ & $\mathrm{~B}$ and $\mathrm{Cl}$ & $p$ & $\mathrm{~B}$ and $\mathrm{Cl}$ & $p$ & $\mathrm{~B}$ and $\mathrm{Cl}$ & $p$ \\
\hline Age & $0.45(0.33-0.58)$ & $<.001$ & $0.44(0.32-0.56)$ & $<.001$ & $0.63(0.43-0.84)$ & $<.001$ & $0.64(0.44-0.84)$ & $<.001$ \\
\hline \multicolumn{9}{|l|}{ Highest parental education } \\
\hline Bachelor's degree or above & Reference & & Reference & & Reference & & Reference & \\
\hline Below a Bachelor's degree & $\begin{array}{l}-0.82(-1.31- \\
-0.33)\end{array}$ & .001 & $\begin{array}{l}-0.94(-1.43-- \\
0.45)\end{array}$ & $<.001$ & $\begin{array}{l}-1.25(-2.14-- \\
0.35)\end{array}$ & .006 & $\begin{array}{l}-1.27(-2.16-- \\
0.38)\end{array}$ & .005 \\
\hline \multicolumn{9}{|l|}{ School type } \\
\hline Private college/university & Reference & & Reference & & Reference & & Reference & \\
\hline State university & $\begin{array}{l}-0.65(-1.25-- \\
0.06)\end{array}$ & .03 & $\begin{array}{l}-0.92(-1.50-- \\
0.33)\end{array}$ & .002 & $\begin{array}{l}-0.33(-1.22- \\
0.55)\end{array}$ & .46 & $\begin{array}{l}-0.35(-1.23- \\
0.54)\end{array}$ & .44 \\
\hline Technical college & $\begin{array}{l}-1.17(-1.82-- \\
0.51)\end{array}$ & .001 & $\begin{array}{l}-1.39(-2.04-- \\
0.74)\end{array}$ & $<.001$ & $\begin{array}{l}-2.15(-3.58-- \\
0.73)\end{array}$ & .003 & $\begin{array}{l}-2.28(-3.68-- \\
0.89)\end{array}$ & .001 \\
\hline $\mathrm{HBCU}$ & $\begin{array}{l}-0.45(-1.35- \\
0.44)\end{array}$ & .32 & $\begin{array}{l}-1.75(-2.46-- \\
1.03)\end{array}$ & $<.001$ & $\begin{array}{l}-0.87(-3.34- \\
1.59)\end{array}$ & .49 & $\begin{array}{l}-1.25(-3.42- \\
0.92)\end{array}$ & .26 \\
\hline \multicolumn{9}{|l|}{ Intersecting identities } \\
\hline Being White and heterosexual & Reference & & & & Reference & & & \\
\hline Being White and sexual minority & $1.45(0.58-2.32)$ & .001 & & & $0.94(-0.51-2.38)$ & .20 & & \\
\hline Being Black and heterosexual & $\begin{array}{l}-1.39(-2.07- \\
-0.72)\end{array}$ & $<.001$ & & & $\begin{array}{l}-0.64(-2.07- \\
0.78)\end{array}$ & .37 & & \\
\hline Being Black and sexual minority & $0.32(-0.89-1.53)$ & .61 & & & $0.54(-2.29-3.37)$ & .71 & & \\
\hline \multicolumn{9}{|l|}{ Experience of discrimination } \\
\hline No discrimination & & & Reference & & & & Reference & \\
\hline Only racial discrimination & & & $\begin{array}{l}-0.003(-0.50- \\
0.49)\end{array}$ & .99 & & & $0.10(-0.83-1.03)$ & .83 \\
\hline Only sexual orientation discrimination & & & $0.37(-0.78-1.52)$ & .52 & & & $1.14(-0.74-3.01)$ & .23 \\
\hline \multirow{2}{*}{$\begin{array}{l}\text { Both racial and sexual orientation } \\
\text { discrimination }\end{array}$} & & & $1.65(0.56-2.73)$ & .003 & & & $0.50(-1.40-2.39)$ & .61 \\
\hline & Adj $R^{2}=0.08$ & & Adj $R^{2}=0.06$ & & Adj $R^{2}=0.07$ & & Adj $R^{2}=0.06$ & \\
\hline
\end{tabular}

HBCU Historically Black Colleges/Universities, B Beta, $\mathrm{Cl}$ Confidence Interval, $p$ Probability Value, $R^{2}$ Coefficient of Determination

reporting racial discrimination, reporting sexual orientation discrimination, and school type.

Multivariable logistic regression models (shown in Table 5) indicated that, compared to White heterosexual women, Black heterosexual women $(\mathrm{OR}=1.72, p=0.02)$, Black sexual minority women $(\mathrm{OR}=2.81, p=0.007)$, and White sexual minority women $(\mathrm{OR}=3.01, p<0.001)$ were all more likely to use marijuana. Compared to women who experienced no discrimination, women who experienced racial $(\mathrm{OR}=1.48, p=0.03)$ or sexual orientation discrimination $(\mathrm{OR}=3.07, p=0.001)$ or both forms of discrimination $(\mathrm{OR}=3.38, p<0.001)$ were more likely to use marijuana. Compared to White heterosexual men, White sexual minority men (OR $=2.37, p=0.009)$ were more likely to use marijuana. Finally, compared to attending a private school, women attending a state university were more likely to use marijuana. In men, however, this effect was reversed, such that men attending a state university were less likely to use marijuana.

\section{Discussion}

This study examines the impacts of intersecting identities versus experiences of discrimination in a sample of young adult college students in Georgia and documents several insightful findings. Results from our study highlight the complex and differential influences of intersecting identities versus intersecting experiences of discrimination on mental health and substance use outcomes. It is clear that in relation to these outcomes, identities and experiences of discrimination do not yield the same effects. Below, in turn, we discuss the implications of our findings for measurement in health disparities research. We also discuss how our findings inform research on experiences of discrimination for women 
Table 4 Multivariable logistic regressions on sociodemographic characteristics, intersecting identities, and intersecting experiences of discrimination and outcome of use of any tobacco products in the past 30 days

\begin{tabular}{|c|c|c|c|c|c|c|c|c|c|}
\hline & \multicolumn{4}{|c|}{ Women's use of tobacco products } & \multicolumn{5}{|c|}{ Men's use of tobacco products } \\
\hline & \multirow{2}{*}{$\begin{array}{l}\text { Model with intersecting } \\
\text { identities } \\
\text { OR and } \mathrm{Cl}\end{array}$} & \multicolumn{3}{|c|}{$\begin{array}{l}\text { Model with intersecting } \\
\text { experiences of } \\
\text { discrimination }\end{array}$} & \multirow{2}{*}{$\begin{array}{l}\text { Model with intersecting } \\
\text { identities } \\
\text { OR and Cl }\end{array}$} & \multicolumn{4}{|c|}{$\begin{array}{l}\text { Model with intersecting } \\
\text { experiences of } \\
\text { discrimination }\end{array}$} \\
\hline & & $p$ & $\mathrm{OR}$ and $\mathrm{Cl}$ & $p$ & & $p$ & OR & $\mathrm{Cl}$ & $p$ \\
\hline Age & $1.04(0.96-1.13)$ & .32 & $\begin{array}{l}1.04(0.97- \\
1.13)\end{array}$ & .28 & $0.98(0.89-1.07)$ & .60 & 0.99 & $\begin{array}{l}(0.90- \\
1.08)\end{array}$ & .76 \\
\hline \multicolumn{10}{|l|}{ Highest parental education } \\
\hline Bachelor's degree or above & Reference & & Reference & & Reference & \multicolumn{4}{|c|}{ Reference } \\
\hline Below a Bachelor's degree & $1.06(0.76-1.49)$ & .72 & $\begin{array}{l}1.07(0.77- \\
1.49)\end{array}$ & .68 & $0.70(0.47-1.04)$ & .08 & 0.71 & $\begin{array}{l}(0.48- \\
1.04)\end{array}$ & .08 \\
\hline \multicolumn{10}{|l|}{ School type } \\
\hline Private college/university & Reference & & Reference & & Reference & \multicolumn{4}{|c|}{ Reference } \\
\hline State university & $1.84(1.19-2.86)$ & .006 & $\begin{array}{l}1.72(1.12- \\
2.65)\end{array}$ & .01 & $1.57(1.07-2.30)$ & .02 & 1.58 & $\begin{array}{l}(1.07- \\
2.31)\end{array}$ & .02 \\
\hline Technical college & $3.00(1.93-4.66)$ & $<.001$ & $\begin{array}{l}2.79(1.80- \\
4.32)\end{array}$ & $<.001$ & $2.31(1.29-4.14)$ & .005 & 2.13 & $\begin{array}{l}(1.20- \\
3.78)\end{array}$ & .01 \\
\hline $\mathrm{HBCU}$ & $1.98(1.10-3.57)$ & .02 & $\begin{array}{l}1.87(1.14- \\
3.04)\end{array}$ & .01 & $2.64(0.93-7.46)$ & .07 & 1.95 & $\begin{array}{l}(0.79- \\
4.80)\end{array}$ & .15 \\
\hline \multicolumn{10}{|l|}{ Intersecting identities } \\
\hline Being White and heterosexual & Reference & & & & Reference & & & & \\
\hline Being White and sexual minority & $2.21(1.32-3.70)$ & .003 & & & $0.96(0.51-1.79)$ & .89 & & & \\
\hline Being Black and heterosexual & $1.16(0.75-1.78)$ & .51 & & & $0.64(0.34-1.24)$ & .19 & & & \\
\hline Being Black and sexual minority & $2.64(1.39-5.02)$ & .003 & & & $1.06(0.33-3.35)$ & .93 & & & \\
\hline \multicolumn{10}{|l|}{ Experience of discrimination } \\
\hline No discrimination & & & Reference & & & & Refer & ence & \\
\hline Only racial discrimination & & & $\begin{array}{l}1.42(1.02- \\
1.98)\end{array}$ & .04 & & & 0.85 & $\begin{array}{l}(0.57- \\
1.27)\end{array}$ & .43 \\
\hline Only sexual orientation discrimination & & & $\begin{array}{l}1.51(0.71- \\
3.21)\end{array}$ & .28 & & & 0.79 & $\begin{array}{l}(0.34- \\
1.87)\end{array}$ & .59 \\
\hline $\begin{array}{l}\text { Both racial and sexual orientation } \\
\text { discrimination }\end{array}$ & & & $\begin{array}{l}3.45(1.97- \\
6.05)\end{array}$ & $<.001$ & & & 1.20 & $\begin{array}{l}(0.55- \\
2.61)\end{array}$ & .64 \\
\hline
\end{tabular}

HBCU Historically Black Colleges/Universities, OR Odd Ratio, Cl Confidence Interval, $p$ Probability Value

and men. Moreover, we integrate our results with existing studies in the literature looking at the associations between race, sexual orientation, and experiences of discrimination and substance use and mental health.

For example, experiences of both forms of discrimination were associated with worse mental health and higher substance use for women. However, among women, compared to those who identified as White and heterosexual, those who identified as White sexual minority had higher risks for all outcomes, while Black sexual minority had higher odds of using tobacco products and marijuana. Among men, compared to those who identified as White and heterosexual, those who identified as White sexual minority had higher depressive symptoms and odds of using marijuana, but no significant higher risks were observed for Black heterosexual or sexual minority. In addition, we did not find support for the "multiple jeopardy" approach, which asserts that additions of "low"status identities (e.g., Black or sexual minority) equate incremental disadvantages [27, 28]. Rather, our results are consistent with the "intersectionality paradox" and highlight the complexity when thinking about how "low"status identities interact with "high"-status identities to produce differences in health behaviors and outcomes [4].

These results have implications for measurement in health disparities research. Researchers need to distinguish between domains of identities and experiences of discrimination by including items capturing intersections within each domain. While we asked about interpersonal experience with discrimination in this study, discrimination can also be conceptualized to include structural inequalities such as lack of access to quality healthcare or internalized racism and homo phobia [37, 38]. 
Table 5 Multivariable logistics regressions on sociodemographic characteristics, intersecting identities, and intersecting experiences of discrimination and outcome of use of marijuana in the past 30 days

\begin{tabular}{|c|c|c|c|c|c|c|c|c|}
\hline & \multicolumn{4}{|c|}{ Women's use of marijuana } & \multicolumn{4}{|c|}{ Men's use of marijuana } \\
\hline & \multicolumn{2}{|c|}{$\begin{array}{l}\text { Model with } \\
\text { intersecting identities }\end{array}$} & \multicolumn{2}{|c|}{$\begin{array}{l}\text { Model with intersecting } \\
\text { experiences of } \\
\text { discrimination }\end{array}$} & \multicolumn{2}{|c|}{$\begin{array}{l}\text { Model with } \\
\text { intersecting identities }\end{array}$} & \multicolumn{2}{|l|}{$\begin{array}{l}\text { Model with } \\
\text { intersecting } \\
\text { experiences of } \\
\text { discrimination }\end{array}$} \\
\hline & $\mathrm{OR}$ and $\mathrm{Cl}$ & $p$ & $\mathrm{OR}$ and $\mathrm{Cl}$ & $p$ & $\mathrm{OR}$ and $\mathrm{Cl}$ & $p$ & $\mathrm{OR}$ and $\mathrm{Cl}$ & $p$ \\
\hline Age & $1.00(0.92-1.10)$ & .93 & $1.00(0.92-1.10)$ & .96 & $0.92(0.82-1.03)$ & .13 & $0.91(0.82-1.02)$ & .11 \\
\hline \multicolumn{9}{|l|}{ Highest parental education } \\
\hline Bachelor's degree or above & Reference & & Reference & & Reference & & Reference & \\
\hline Below a Bachelor's degree & $0.88(0.62-1.25)$ & .47 & $0.88(0.62-1.25)$ & .47 & $1.06(0.64-1.75)$ & .82 & $1.10(0.67-1.80)$ & .72 \\
\hline \multicolumn{9}{|l|}{ School type } \\
\hline Private college/university & Reference & & Reference & & Reference & & Reference & \\
\hline State university & $1.91(1.25-2.94)$ & .003 & $1.85(1.21-2.82)$ & .004 & $0.48(0.29-0.79)$ & .004 & $0.48(0.29-0.79)$ & .004 \\
\hline Technical college & $1.00(0.59-1.70)$ & .99 & $0.99(0.59-1.66)$ & .96 & $0.40(0.16-1.03)$ & .06 & $0.40(0.16-0.99)$ & .05 \\
\hline $\mathrm{HBCU}$ & $1.58(0.86-2.90)$ & .14 & $2.04(1.24-3.35)$ & .005 & $1.29(0.38-4.36)$ & .69 & $1.19(0.43-3.33)$ & .74 \\
\hline \multicolumn{9}{|l|}{ Intersecting identities } \\
\hline Being White and heterosexual & Reference & & & & Reference & & & \\
\hline Being White and sexual minority & $3.01(1.77-5.12)$ & $<.001$ & & & $2.37(1.24-4.49)$ & .009 & & \\
\hline Being Black and heterosexual & $1.72(1.07-2.75)$ & .02 & & & $0.90(0.37-2.16)$ & .81 & & \\
\hline Being Black and sexual minority & $2.81(1.33-5.92)$ & .007 & & & $3.01(0.88-10.27)$ & .08 & & \\
\hline \multicolumn{9}{|l|}{ Experience of discrimination } \\
\hline No discrimination & & & Reference & & & & Reference & \\
\hline Only racial discrimination & & & $1.48(1.03-2.13)$ & .03 & & & $1.10(0.66-1.84)$ & .71 \\
\hline Only sexual orientation discrimination & & & $3.07(1.58-5.99)$ & .001 & & & $0.93(0.31-2.74)$ & .89 \\
\hline Both racial and sexual orientation discrimination & & & $3.38(1.80-6.31)$ & $<.001$ & & & $2.04(0.86-4.84)$ & .11 \\
\hline
\end{tabular}

HBCU Historically Black Colleges/Universities, OR Odd Ratio, Cl Confidence Interval, $p$ Probability Value

Our findings contribute to existing literature on the impacts of discrimination on health for college students and young adults. Several studies have documented that perceived racial discrimination is linked to higher depressive symptoms and higher alcohol and tobacco use among Black college students [39-42] and higher alcohol use among White students [43, 44]. Some research has also investigated differential impacts based on sex; for example, a study found that while Black men with more lifetime discrimination had a positive association between daily negative mood and level of nonsocial drinking, this association was reversed in women [45]. In addition, recent research has also examined discrimination encountered by sexual minority students and its link to mental health [46].

Our findings extend this literature by examining effects of different types of discrimination on outcomes among women and men. Our study provides evidence for how experience of discrimination was a strong predictor of higher depressive symptoms and higher substance use for female young adults as well as how patterns of influence of intersecting experience of discrimination on these outcomes differed between male and female young adults. Compared to those experiencing no discrimination, women experiencing a single form of discrimination had higher depressive symptoms and higher odds of using tobacco products and marijuana. Experiencing of both forms of discrimination put women at higher depressive symptoms and higher substance use than experiencing only a single form of discrimination. The effects were not similar among men. Compared to men who did not experience discrimination, those who experienced either racial or sexual orientation discrimination had higher depressive symptoms, but we did not observe any effect of experiencing both forms of discrimination. Thus, research and initiatives to address discrimination and prejudices should pay close attention to the deleterious impacts of discrimination on women's health, and future studies should continue to investigate effects of different types of discrimination and variations of effects between men and women.

Our results also echo Bauer's (2014) recommendations for methodological application of intersectionality in public health, in particular through approaches to construct 
models that make intersectional effects visible to readers [5]. Here we presented one approach to structuring analytical models that helps readers understand how the impact of factors (intersecting identities and experience of discrimination) differed across strata (men and women). Through stratifying our analyses by sex, we found that the differences in all four outcomes along the line of intersecting identities and experience of discrimination were more prominent for women compared to men.

Prior literature has documented more significant risk of substance use for sexual minority women when compared with heterosexual women, and studies also found smaller effect sizes in use among men by sexual orientations [9, 47-50]. For example, data from the National Alcohol Survey suggested that sexual minority adult women had lower alcohol abstention rates and greater odds of reporting alcohol-related problems compared to heterosexual women. The same data showed that few significant differences in use of alcohol and experience of alcohol-related problems existed among men by sexual orientation [49]. Additionally, McCabe and colleagues analyzed data from the National Epidemiologic Survey on Alcohol and Related Conditions [48] to examine substance use and dependence (alcohol, marijuana, and other drugs) and found that the effects of sexual minority status on substance use and substance dependence were larger for women than for men. Moreover, a survey of undergraduate students on drug use showed that sexual minority women were more likely to use marijuana and smoke cigarettes compared to heterosexual women [51]. Among men, the survey found that sexual minority men were less likely to drink more heavily compared to heterosexual men.

Our results are consistent with some of these conclusions in the literature, though, of note, our findings provide novel information because we included racial status in addition to sexual orientation. In our study, while White sexual minority men had higher odds of using marijuana compared to White heterosexual men; no other significant differences were observed for other outcomes or for Black heterosexual and Black sexual minority men. Among women, as mentioned, we found more variations, and also found evidence of sexual minority women with higher risks on a few outcomes compared to heterosexual women (e.g., White sexual minority women had higher use of all substance compared to White heterosexual women, and Black sexual minority women had higher use of tobacco products and marijuana compared to White heterosexual women). However, it should be noted that while some studies found higher or comparable rates of substance use among sexual minority women of color compared to White sexual minority women $[9,52]$, our study did not replicate this pattern. More research is needed to understand intersectional differences in substance use for women.

\section{Strengths and limitations}

The generalizability of findings is limited because our sample was drawn from young adult college students in Georgia. However, it is important to note that our sample was drawn from diverse schools, including private, public, technical, and historically black colleges and universities in both rural and urban settings. We also limited our analysis to only Black and White students and did not consider non-White Hispanic and Asian students due to the small size of these groups in our sample. Future studies with larger sample size of these populations should continue to investigate the interplay between intersecting identities and experiences of discrimination.

Additionally, in our study, we grouped students identifying as homosexual and students identifying as bisexual into one ("sexual minority") due to the small sample size of each category. Some research has shown differences in substance use between homosexual versus bisexual college students [53, 54]. Future studies may want to over sample these different categories in order to further understand whether differences exist in regards to mental health and substance use between different sexual minority categories.

While our data was limited by being self-reported, cross-sectional data, the data included key measures, including the assessment of use of different substance (alcohol, diverse alternative tobacco products, and marijuana). Most importantly, as highlighted throughout this paper, the inclusion of items capturing intersecting identities and experience of discrimination allowed us to separate influences of minority statuses versus discrimination on health behaviors and outcomes.

\section{Conclusions}

This study continues the efforts to conceptualize and operationalize intersectionality in public health research and contributes to a developing body of literature that applies intersectionality theory to understand health disparities [3-8]. We provide empirical data to support the "intersectionality paradox" argument and suggest that researchers should not assume that health risks increase with each additional minority status. Future studies should distinguish between and jointly assess intersecting social positions (e.g., identities) and processes (e.g., interpersonal experience of discrimination or forms of structural oppression). Given the large number of potential identities (e.g., sex, race, ethnicity, sexual orientation, class, age, weight, religion, immigration status) and experiences that can be related to these identities, we recommend that researchers use robust theory and evidence to guide their selection of variables. Attention should also be paid to model constructions in order to make intersectional effects visible to readers. Furthermore, subsequent 
steps to advance intersectionality theory can include investigations of the dynamic nature of identities and how identities or experience of different processes change or remain in different contexts and across lifespan development. We believe such considerations will contribute to the growing field of intersectional health research and further efforts to achieve health equity.

\section{Abbreviations}

B: Beta; DECOY: Documenting experiences with cigarettes and other tobacco in young adults; DSM: Diagnostic and Statistical Manual of Mental Disorders; HBCU: Historically Black Colleges/Universities; IRB: Institutional Review Board; OR: Odd ratio; P: Probability value; PHQ-9: Patient heath questionnaire - 9; SD: Standard deviation

\section{Acknowledgements}

We would like to thank our Campus Advisory Board members across the state of Georgia in developing and assisting in administering this survey. We also would like to thank ICF Macro for their scientific input and technical support in conducting this research.

\section{Funding}

This research was supported by the National Cancer Institute (1R01CA179422-01; PI: Berg). The funders had no role in the study design, collection, analysis or interpretation of the data, writing the manuscript, or the decision to submit the paper for publication.

\section{Availability of data and materials}

The datasets used and/or analyzed during the current study are available from the senior author (Dr. Carla J. Berg) on reasonable request.

\section{Authors' contributions}

MV conceptualized the study, performed data analysis, and wrote the manuscript. JL contributed to the conceptualization of the study, reviewed data analytical methods, and contributed to manuscript writing. $\mathrm{RH}$ and MW reviewed data analytical methods and contributed to manuscript writing. CJB oversaw data collection, reviewed data analytical methods, and contributed to manuscript writing. All authors have read and approved the final manuscript.

\section{Ethics approval and consent to participate}

Our project was approved by the Emory University and ICF Institutional Review Boards (IRBs) as well as the IRBs of the participating colleges and universities: Kennesaw State University, University of North Georgia, Berry College, Albany State University, Athens Technical College, and Central Georgia Technical College. All participants provide consent prior to completing the survey. Electronic consent was obtained from all participants. By clicking a "confirm" button included in an email sent to participants after initial recruitment, participants were launched into the survey.

\section{Consent for publication}

Not applicable because there is no identifiable images, videos, or details relating to an individual person in our manuscript.

\section{Competing interests}

The authors declare that they have no competing interests.

\section{Publisher's Note}

Springer Nature remains neutral with regard to jurisdictional claims in published maps and institutional affiliations.

\section{Author details}

'Department of Behavioral Sciences and Health Education, Rollins School of Public Health, 1518 Clifton Rd NE, Atlanta, GA 30322, USA. ${ }^{2}$ Winship Cancer Institute, 1365 Clifton Rd, Atlanta, CA 30322, USA.
Received: 19 February 2018 Accepted: 11 January 2019

Published online: 23 January 2019

\section{References}

1. Nash J. Intersectionality. Fem Rev. 2008:89:1-15.

2. Crenshaw K. Mapping the margins: Intersectionality, identity politics, and violence against women of color. Stanford Law Rev. 1991;43:1241-99. https://doi.org/10.2307/1229039.

3. Bowleg L. When black + lesbian + woman $\neq$ black lesbian woman: the methodological challenges of qualitative and quantitative intersectionality research. Sex Roles. 2008:59:312-25.

4. Bowleg $L$. The problem with the phrase women and minorities: Intersectionality-an important theoretical framework for public health. Am J Public Health. 2012;102:1267-73.

5. Bauer GR. Incorporating intersectionality theory into population health research methodology: challenges and the potential to advance health equity. Soc Sci Med. 2014;110:10-7.

6. Seng JS, Lopez WD, Sperlich M, Hamama L, Reed Meldrum CD. Marginalized identities, discrimination burden, and mental health: empirical exploration of an interpersonal-level approach to modeling intersectionality. Soc Sci Med. 2012;75:2437-45

7. López N, Gadsden VL. Health Inequities, Social Determinants, and Intersectionality; 2016

8. Rosenfield S. Triple jeopardy? Mental health at the intersection of gender race, and class. Soc Sci Med. 2012;74:1791-801.

9. Mereish $\mathrm{EH}$, Bradford JB. Intersecting identities and substance use problems: sexual orientation, gender, race, and lifetime substance use problems. J Stud Alcohol Drugs. 2014;75:179-88. https://doi.org/10.15288/jsad.2014.75. 179.

10. Van Herk KA, Smith D, Andrew C. Examining our privileges and oppressions: incorporating an intersectionality paradigm into nursing. Nurs Inq. 2011:18: 29-39. https://doi.org/10.1111/j.1440-1800.2011.00539.x.

11. Mill J, Edwards N, Jackson R, Austin W, MacLean L, Reintjes F. Accessing health services while living with HIV: intersections of stigma. Can J Nurs Res. 2009:41:168-85

12. Viruell-Fuentes EA, Miranda PY, Abdulrahim S. More than culture: structural racism, intersectionality theory, and immigrant health. Soc Sci Med. 2012;75: 2099-106.

13. Meyer $\mid H$. Prejudice, social stress, and mental health in lesbian, gay, and bisexual populations: conceptual issues and research evidence. Psychol Bull. 2003;129:674-97. https://doi.org/10.1037/0033-2909.129.5.674.

14. Grollman EA. Multiple forms of perceived discrimination and health among adolescents and young adults. J Health Soc Behav. 2012;53:199-214. https://doi.org/10.1177/0022146512444289.

15. Wong CF, Schrager SM, Holloway IW, Meyer IH, Kipke MD. Minority stress experiences and psychological well-being: the impact of support from and connection to social networks within the Los Angeles house and ball communities. Prev Sci. 2014;15:44-55. https://doi.org/10.1007/s11121-012-0348-4.

16. American Psychological Association. Stress in America: the impact of discrimination. Washington, D.C: American Psychological Association; 2015. http://www.apa.org/news/press/releases/stress/2015/impact-ofdiscrimination.pdf.

17. Clark R, Anderson NB, Clark VR, Williams DR. Racism as a stressor for African Americans. A biopsychosocial model. Am Psychol. 1999;54:805-16.

18. Stuber J, Meyer I, Link B. Stigma, prejudice, discrimination and health. Soc Sci Med. 2008;67:351-7. https://doi.org/10.1016/j.socscimed.2008.03.023.

19. Pascoe EA, Richman LS. Perceived discrimination and health: a meta-analytic review. Psychol Bull. 2009;135:531-54.

20. Brody GH, Kogan SM, Chen Y. Perceived discrimination and longitudinal increases in adolescent substance use: gender differences and mediational pathways. Am J Public Health. 2012;102:1006-11. https://doi.org/10.2105/ AJPH.2011.300588.

21. Gerrard M, Stock ML, Roberts ME, Gibbons FX, O'Hara RE, Weng C-Y, et al. Coping with racial discrimination: the role of substance use. Psychol Addict Behav. 2012;26:550-60. https://doi.org/10.1037/a0027711.

22. Hatzenbuehler ML, Corbin WR, Fromme K. Discrimination and alcoholrelated problems among college students: a prospective examination of mediating effects. Drug Alcohol Depend. 2011;115:213-20. https://doi.org/ 10.1016/j.drugalcdep.2010.11.002

23. Purnell JQ, Peppone LJ, Alcaraz K, McQueen A, Guido JJ, Carroll JK, et al. Perceived discrimination, psychological distress, and current smoking status: 
results from the behavioral risk factor surveillance system reactions to race module, 2004-2008. Am J Public Health. 2012;102:844-51. https://doi.org/10. 2105/AJPH.2012.300694.

24. Gibbons FX, Gerrard M, Cleveland MJ, Wills TA, Brody G. Perceived discrimination and substance use in African American parents and their children: a panel study. J Pers Soc Psychol. 2004;86:517-29. https://doi.org/ 10.1037/0022-3514.86.4.517.

25. Guthrie BJ, Young AM, Williams DR, Boyd CJ, Kintner EK. African American girls' smoking habits and day-to-day experience with racial discrimination. Nurs Res. 2002:51:183-90.

26. Meyer IH, Schwartz S, Frost DM. Social patterning of stress and coping: does disadvantaged social statuses confer more stress and fewer coping resources? Soc Sci Med. 2008;67:368-79.

27. Lee J, Scott D, Floyd MF. Structural inequalities in outdoor recreation participation: a multiple hierarchy stratification perspective. J Leis Res. 2001;33:427-49.

28. Shores KA, Scott D, Floyd MF. Constraints to outdoor recreation: a multiple hierarchy stratification perspective. Leis Sci. 2007;29:227-46.

29. Warner DF, Brown TH. Understanding how race/ethnicity and gender define age-trajectories of disability: an intersectionality approach. Soc Sci Med. 2011;72:1236-48. https://doi.org/10.1016/j.socscimed.2011.02.034.

30. Orr ST, Blazer DG, James SA. Racial disparities in elevated prenatal depressive symptoms among black and white women in eastern North Carolina. Ann Epidemiol. 2006;16:463-8.

31. Dermody SS, Marshal MP, Cheong JW, Burton C, Hughes T, Aranda F, et al. Longitudinal disparities of hazardous drinking between sexual minority and heterosexual individuals from adolescence to Young adulthood. J Youth Adolesc. 2014:43:30-9.

32. Berg CJ, Haardörfer R, Lewis M, Getachew B, Lloyd SA, Thomas SF, et al. DECOY: documenting experiences with cigarettes and other tobacco in Young adults. Am J Health Behav. 2016;40:310-21.

33. Coker TR, Elliott MN, Kanouse DE, Grunbaum JA, Schwebel DC, Gilliland MJ, et al. Perceived racial/ethnic discrimination among fifth-grade students and its association with mental health. Am J Public Health. 2009;99(5):878-84.

34. Greene ML, Way N, Pahl K. Trajectories of perceived adult and peer discrimination among black, Latino, and Asian American adolescents: patterns and psychological correlates. Dev Psychol. 2006;42(2):218-36.

35. Löwe B, Spitzer RL, Gräfe K, Kroenke K, Quenter A, Zipfel S, et al. Comparative validity of three screening questionnaires for DSM-IV depressive disorders and physicians' diagnoses. J Affect Disord. 2004:78:131-40.

36. National Health Service. Patient Health Questionnaire. 2016. http://www. datadictionary.nhs.uk/data_dictionary/nhs_business_definitions/p/patient_ health_questionnaire-9_de.asp?shownav=1. Accessed 22 Jan 2017.

37. Williams DR, Mohammed SA. Discrimination and racial disparities in health: evidence and needed research. J Behav Med. 2009;32:20-47. https://doi.org/ 10.1007/s10865-008-9185-0

38. Williams DR, Neighbors HW, Jackson JS. Racial/ethnic discrimination and health: findings from community studies. Am J Public Health. 2003;93:200-8.

39. Prelow HM, Mosher CE. Bowman M a. Perceived racial discrimination, social support, and psychological adjustment among African American college students. J Black Psychol. 2006:32:442-54.

40. Bennett GG, Wolin KY, Robinson EL, Fowler S, Edwards CL. Perceived racial/ ethnic harassment and tobacco use among African American Young adults. Am J Public Health. 2005;95:238-40. https://doi.org/10.2105/AJPH.2004. 037812

41. Metzger IW, Cooper SM, Ritchwood TD, Onyeuku C, Griffin CB. Profiles of African American college students' alcohol use and sexual behaviors: associations with stress, racial discrimination, and social support. J Sex Res. 2017:54:374-85. https://doi.org/10.1080/00224499.2016.1179709.

42. Hoggard LS, Byrd CM, Sellers RM. The lagged effects of racial discrimination on depressive symptomology and interactions with racial identity. J Couns Psychol. 2015;62:216-25. https://doi.org/10.1037/cou0000069.

43. Broman CL. Perceived discrimination and alcohol use among black and white college students. J Alcohol Drug Educ. 2007;51:8-16

44. Grekin ER. Perceived racism and alcohol consequences among african american and caucasian college students. Psychol Addict Behav. 2012;26: 924-30. https://doi.org/10.1037/a0029593.

45. O'Hara RE, Armeli S, Scott DM, Covault J, Tennen H. Perceived racia discrimination and negative-mood-related drinking among African American college students. J Stud Alcohol Drugs. 2015;76:229-36.
46. Woodford MR, Han Y, Craig S, Lim C, Matney MM. Discrimination and mental Health among sexual minority college students: the type and form of discrimination does matter. J Gay Lesbian Ment Health. 2014;18:142-63.

47. McCabe SE, Hughes TL, Bostwick W, Boyd CJ. Assessment of difference in dimensions of sexual orientation: implications for substance use research in a college-age population. J Stud Alcohol. 2005;66:620-9.

48. McCabe SE, Hughes TL, Bostwick WB, West BT, Boyd CJ. Sexual orientation, substance use behaviors and substance dependence in the United States. Addiction. 2009:104:1333-45.

49. Drabble L, Midanik LT, Trocki K. Reports of alcohol consumption and alcohol-related problems among homosexual, bisexual and heterosexual respondents: results from the 2000 National Alcohol Survey. J Stud Alcohol. 2005;66:111-20. https://doi.org/10.15288/jsa.2005.66.111.

50. Burgard SA, Cochran SD, Mays VM. Alcohol and tobacco use patterns among heterosexually and homosexually experienced California women. Drug Alcohol Depend. 2005;77:61-70.

51. McCabe SE, Boyd C, Hughes TL, D'Arcy H. Sexual identity and substance use among undergraduate students. Subst Abus. 2003;24:77-91.

52. Hughes TL, Wilsnack SC, Szalacha LA, Johnson T, Bostwick WB, Seymour R, et al. Age and racial/ethnic differences in drinking and drinking-related problems in a community sample of lesbians. J Stud Alcohol. 2006;67:579-90.

53. Ford JA, Jasinski JL. Sexual orientation and substance use among college students. Addict Behav. 2006;31:404-13.

54. Eisenberg $\mathrm{M}$, Wechsler $\mathrm{H}$. Substance use behaviors among college students with same-sex and opposite-sex experience: Results from a national study. Addict Behav. 2003;28:899-913.
Ready to submit your research? Choose BMC and benefit from:

- fast, convenient online submission

- thorough peer review by experienced researchers in your field

- rapid publication on acceptance

- support for research data, including large and complex data types

- gold Open Access which fosters wider collaboration and increased citations

- maximum visibility for your research: over $100 \mathrm{M}$ website views per year

At BMC, research is always in progress.

Learn more biomedcentral.com/submissions 